\title{
Innovation in rehabilitation technology: technological opportunities and socioeconomic implications - a theoretical model
}

\section{Giuseppe Turchetti*}

E - TX - MAN Research Centre and MAIN Lab, Scuola Superiore Sant'Anna, Piazza Martiri della Libertà, 33 - 56127 Pisa, Italy

E-mail: g.turchetti@sssup.it

*Corresponding author

\section{Barbara Labella}

Quality and Accreditation Department, National Agency for Healthcare Services, Via Puglie, 23 - 00187 Roma, Italy

E-mail: labella@agenas.it

\section{Stefania Bellelli, Sara Cannizzo and} Ilaria Palla

E - TX - MAN Research Centre and MAIN Lab, Scuola Superiore Sant'Anna,

Piazza Martiri della Libertà, 33 - 56127 Pisa, Italy

E-mail: s.bellelli@sssup.it

E-mail: s.cannizzo@sssup.it

E-mail: i.palla@sssup.it

\section{Stefano Mazzoleni}

ARTS Lab (Advanced Robotics Technology and Systems) Polo Sant'Anna Valdera, Scuola Superiore Sant'Anna,

Viale R. Piaggio, 34 - 56025 Pontedera (Pisa), Italy

E-mail: stefano.mazzoleni@arts.sssup.it

\section{Silvia Petroni}

Laboratory of Biomedical Robotics and Biomicrosystems, CIR-Center for Integrated Research, Università Campus Bio-Medico, Via Álvaro del Portillo, 21 - 00128 Roma, Italy

E-mail: s.petroni@unicampus.it 


\section{Silvia Sterzi}

Clinical Unit of Physical Medicine and Rehabilitation,

CIR-Center for Integrated Research,

Università Campus Bio-Medico,

Via Álvaro del Portillo, 21 - 00128 Roma, Italy

E-mail: s.sterzi@unicampus.it

\section{Eugenio Guglielmelli}

Laboratory of Biomedical Robotics and Biomicrosystems, CIR-Center for Integrated Research, Università Campus Bio-Medico,

Via Álvaro del Portillo, 21 - 00128 Roma, Italy

E-mail: e.guglielmelli@unicampus.it

Abstract: Innovation in stroke rehabilitation technology is discussed that, based on published epidemiological and economic data, represents an urgent case to deal with adopting a multidisciplinary perspective. A theoretical model is proposed for the evaluation of socioeconomic implications related to an early diagnosis and early and timely adjustments in the stroke treatment strategy. The model is applied to the case of a new rehabilitation technology: the ALLADIN diagnostic device. The model compares a traditional approach - 'trial and error strategy' - to the innovative one - 'in progress evaluation', considering the diagnostic and rehabilitative steps of the patient's assistive route and assessing social and economic benefits of the innovative device. The new technology allows a precise initial assessment of both the severity of stroke and the level of lost functionality, as long as an evaluation of the expected return from different potential therapies. Moreover, supposing that higher severity of stroke implies higher level of disabilities and social costs, and that the negative impact increases as the level of disability increases, the use of innovative rehabilitation technologies would be more effective in the case of patients with severe and very severe stroke.

Keywords: costs; disability; economic evaluation; rehabilitation technology; stroke, theoretical model.

Reference to this paper should be made as follows: Turchetti, G., Labella, B., Bellelli, S., Cannizzo, S., Palla, I., Mazzoleni, S., Petroni, S., Sterzi, S. and Guglielmelli, E. (2009) 'Innovation in rehabilitation technology: technological opportunities and socioeconomic implications - a theoretical model', Int. J. Healthcare Technology and Management, Vol. 10, Nos. 4/5, pp.245-261.

Biographical notes: Giuseppe Turchetti received his Laurea Degree in Economics from the University of Pisa and his $\mathrm{PhD}$ in Economics and Management from the Scuola Superiore Sant'Anna (SSSA) in Pisa, where he is an Associate Professor of Economics and Management. He is the Cofounder of the Research Centre on Technologies and Services for the Support of Longevity and of the Research Laboratory on Management and Innovation of SSSA. His main research interests are in the fields of the organisation, financing and evaluation of healthcare services and health technologies. He is author/coauthor of several books and scholarly papers. He is an Associate Editor of the Int. J. Biomedical Engineering and Technology. 
Barbara Labella received her Laurea Degree in economics from the University of Pisa in 2002. From the same university she received her PhD in 2007. She collaborated in several research projects at CRIM (Research Center in Microengineering), ARTS Lab (Advanced Robotics Technology and Systems), ETXMAN (Research Centre on European Transplantation Management) of Scuola Superiore Sant'Anna, and at the Surgical and Transplantation Division of the University of Pisa. She is currently responsible for the Clinical Risk and Patient Safety Area at the Quality and Accreditation Department of National Agency for Healthcare Services in Rome.

Stefania Bellelli is a PhD Student in health technology assessment and management at the University of Pisa, Italy. She received the degree in statistics and actuarial sciences from the University of Florence, Italy, in 2003. She currently works at the European Transplantation Management Centre (ETXMAN Centre) and at the Management \& Innovation (MAIN) Laboratory of the Scuola Superiore Sant'Anna in Pisa, Italy, as a research assistant. Her research interests include health technology assessment, epidemiological and economic evaluations in healthcare.

Sara Cannizzo received her Laurea Degree in economics from the University of Pisa, Italy, in 2004 and her master's in auditing and internal control of financial intermediaries from the Faculty of Economics of the University of Pisa. Since 2004 she has been part of the European Transplantation Management Centre (ETXMAN Centre) and the Management \& Innovation (MAIN) Laboratory at the Scuola Superiore Sant'Anna in Pisa, as a research assistant. Her research interests include economic issues of the healthcare systems and insurance management.

Ilaria Palla graduated in philosophy from the University of Pisa, Italy, in 1997. She received her MS in healthcare management from the Bocconi University in Milan, Italy, in 2005. She works at the European Transplantation Management Centre (ETXMAN Centre) and at the Management \& Innovation (MAIN) Laboratory of the Scuola Superiore Sant'Anna in Pisa, Italy, as a research assistant. Her research interests include health technology assessment and socioeconomic issues of the healthcare systems.

Stefano Mazzoleni received his Laurea degree in Computer Engineering from the University of Pisa and his PhD in Biomedical Engineering from the University of Genoa. Since 2002, he has collaborated with the ARTS Lab, Scuola Superiore Sant'Anna, in different European and national research projects on biomedical engineering. In December 2005, he was Visiting Researcher at the Department of Neurophysiology, Katholieke Universiteit Leuven, Belgium, working on the development of advanced techniques for the preprocessing of biomedical data. Currently, he is a post-doc at the ARTS Lab. His current research interests include rehabilitation robotics, human motor control and functional assessment in neurorehabilitation.

Silvia Petroni received her BS in biomedical engineering from University Campus Bio-Medico in Rome, in 2002. She received her MS in biomedical engineering (with Honours) from University Campus Bio-Medico in Rome, in 2004, and her PhD in biomedical engineering at the same university, in the Laboratory of Robotics and Biomicrosystems. Her research interests include the development of innovative biomechatronic systems for biomedical applications, such as drug delivery, and health technology assessment (HTA). She carries on activity on HTA in cooperation with the Scuola Superiore Sant'Anna in Pisa. 
Silvia Sterzi received her Laurea Degree in Medicine from Catholic University of Rome, and her specialisation in Physical Medicine and Rehabilitation from University of Florence. She has been a Member of the European Board of Physical Medicine and Rehabilitation since 1993. She worked in the House Staff of Physical Medicine and Rehabilitation as Assistant Professor of Physical Medicine and Rehabilitation at Catholic University of Rome, from 1982 to 2004. Currently, she is an Associate Professor of Physical Medicine and Rehabilitation and Director of Postgraduate School of Physical Medicine and Rehabilitation at Campus Bio-Medico University of Rome.

Eugenio Guglielmelli received his Laurea Degree in Electronics Engineering and $\mathrm{PhD}$ in Biomedical Robotics from the University of Pisa. Currently, he is an Associate Professor of Bioengineering at Campus Bio-Medico University of Rome, where he is Head of the Laboratory of Biomedical Robotics and Biomicrosystems. His main research interests are in the fields of humancentred robotics, biomechatronic design and biomorphic control of robotic systems. He is also a author/coauthor of more than 150 papers in international journals, conference proceedings and books. Currently, he is an Associate Editor of the IEEE Robotics and Automation Magazine and Member of the Editorial Board of the Int. J. Applied Bionics and Biomechanics.

\section{Introduction}

The introduction of new and advanced solutions in the biomedical technology sector is a complex process, and it is usually more difficult to achieve than in other fields. Several elements, in fact, may be identified as factors contributing to the complexity of the innovation process such as the multidimensionality of the problems, the requested multidisciplinary approach, the presence of conflicts of interests and resistance in the organisations and in the professionals, the differences in the incentives and time horizon of various players and stakeholders. The social and ethical implications of health-related activities would need also to be considered. Consequently, managing biomedical product development process requires to take into account technological, clinical, economic, social, ethical and legal perspectives that introduce new constraints/objectives of the innovation process such as efficacy, effectiveness, affordability, sustainability, equity, usability, market potential and accessibility.

The paper proposes and discusses a theoretical model for the assessment of social and economic benefits of an innovative technology with the aim to frame the cost-saving implications related to the use of a new device. The model is applied to the stroke case, and it could be generalised to the field of neurological pathologies. Basing on published epidemiological and economic data, stroke represents an urgent case to deal with from an integrated and multidisciplinary perspective that contributes to well framing the clinical, technological and economic scenario in which to move forwards the future/possible commercialisation of innovative technological devices for stroke patients. An early diagnosis is extremely important in terms of recovering functionality after the stroke event, as well as the first months after the occurrence of the disease, requiring an early and timely adjustment in the treatment strategy. With the aim of improving and increasing the effectiveness of the post-stroke rehabilitation, an innovative method for decision support in neurorehabilitation could be achieved through the use of ALLADIN 
(Natural Language-Based Decision Support In Neuro-Rehabilitation) diagnostic device (ADD). The theoretical model proposed in this study compares a traditional approach, pursuing a 'trial and error strategy', to an 'in progress evaluation strategy' carried out by ALLADIN, considering the diagnostic and the rehabilitative steps of the assistive route for a stroke patient. The model allows a precise assessment of both the severity of stroke and the level of lost functionality, as long as an evaluation of the expected returns, pointing out the potential social cost savings related to the application of an innovative technology for neurorehabilitation in stroke, as the ALLADIN device.

In order to define the state of the art of innovation in rehabilitation technology and approaching the matter from an integrated and multidisciplinary perspective, a review of the epidemiological and economic data about stroke has been carried out. In Section 2, the main published epidemiological studies have been analysed in order to estimate, basing on data about stroke incidence, prevalence, mortality and disability, the full market potential of rehabilitation technology. The cost categories of stroke have been defined according to the Cost-of-Illness approach, and a critical analysis of the most relevant published data about the total - and the social - cost of stroke is proposed in order to provide a general frame of costs and potential cost savings related to the use of innovative technology for neurorehabilitation in stroke. In Section 3, an outline of the procedures in assessing the functional recovery outcome in neurorehabilitation after stroke is provided. ADD as a tool supporting the clinical decision making towards the choice of the best rehabilitative process for each patient is described. The theoretical model is proposed and discussed in Section 4, and it is applied to the ADD, showing the social and economic benefits of this new neurorehabilitation technology. Closing remarks are finally argued in Section 5 .

\section{Epidemiological context of stroke and socioeconomic implications}

According to the World Health Organization (WHO) definition, stroke is a clinical syndrome with 'rapidly developing clinical signs of focal or global disturbance of cerebral function, with symptoms lasting 24 hours or longer or leading to death, with no apparent cause other than of vascular origin' (Truelsen, Begg and Mathers, 2003). The main subtypes of stroke are identified as ischaemic stroke, haemorrhagic stroke and subarachnoid haemorrhage. Baseline stroke severity is assessed using the National Institute of Health Stroke Scale, and in agreement with the classification proposed by H.S. Jorgensen, it could be distinguished in four levels: mild, moderate, severe and very severe (Jorgensen et al., 1999). Epidemiological data on disease occurrence are essential for describing the burden of stroke and the post-stroke neurorehabilitation process involved. Together with prevalence, incidence, morbidity and mortality data, cost estimates help to portray the impact that society or an organisation faces from stroke.

\subsection{Epidemiological context of stroke}

The WHO estimates that every year 15 million people worldwide suffer a stroke. Of these, 5 million are left permanently disabled and 5.5 million ( 3 million women and 2.5 million men) die (World Health Organization, 2004). In demographically developed countries, characterised by an older age structure, the mean age at which stroke occurs is around 70 years, while in less developed regions, the average age of stroke will be 
younger due to the different population age structure resulting from higher mortality rates and competing causes of death (Truelsen, Begg, and Mathers, 2003).

Incidence, prevalence and mortality estimates are quite different in the published international and national studies as they strongly depend on the composition of the reference population, in relation to age and sex, on type of stroke and the study design.

Recently, the American Heart Association estimates that each year about 700,000 people experience a new or recurrent stroke in the USA. About 500,000 of these are first attacks. Approximately 200,000 occur in people who have already had a stroke before. Men's stroke incidence rates are greater than women's at younger ages but not at older ages (American Heart Association, 2007). Epidemiological studies have shown that incidence differs widely throughout Europe with a gap between eastern and western European countries. In 1997, crude incidence rates of acute stroke were higher for most eastern (range between 3.0/1,000 and 5.0/1,000) than for western countries (range between 2.0/1,000 and 2.5/1,000) (Brainin et al., 2000). The most recent Italian guide line Stroke Prevention and Educational Awareness Diffusion (SPREAD) indicates that 196,000 cases of stroke occur in Italy every year, $80 \%$ of those are first occurrence of stroke and $20 \%$ are relapses. In all, 39,000 persons with stroke die in the first month after the event and other 58,800 survive with disability (SPREAD, 2005). Italian population-based crude incidence rates are available for six stroke registries and range from 1.79/1,000 in Vibo Valentia to 2.92/1,000 in L'Aquila. Incidence rates increase with age; in regard to persons aged from 65 to 84 years, an European population-based study indicates that the incidence rate is $8.72 / 1,000$ with a corresponding $95 \%$ confidence interval $(95 \% \mathrm{CI})$ between 7.47 and 10.06 (Di Carlo et al., 2000). In the same age class, data from the Italian Longitudinal Study on Aging (ILSA), suggests that sex- and age-standardised incidence rate of stroke is 10.47/1,000 (95\% CI: 8.63-12.32) (SPREAD, 2005).

The American Heart Association reported that among adults aged 20 and older, the prevalence of stroke in 2004 was estimated at 5,700,000 (2,400,000 males, 3,300,000 females) (American Heart Association, 2007). Prevalence rates increase with age, and consistently across age classes, men have higher rates than women. The prevalence rates given in the European survey did not show uniform differences between eastern and western countries. Individuals over 65 years have higher prevalence rates of stroke, varying between 4.61 and $7.33 \%$, as reported by international population-based studies (Feigin et al., 2003). The ILSA study estimates that sex- and age-standardised prevalence rate of stroke is $6.5 \%$ (95\% CI: 4.9-6.9) in persons aged from 65 to 84 years. Prevalence is higher in men $(7.4 \%$; 95\% CI: 6.3-8.5) than in women $(5.9 \%$; 95\% CI: 4.9-6.9) and increases with age (SPREAD, 2005).

Stroke is the third most common cause of death in developed countries, exceeded only by coronary heart disease and cancer, accounting for $10 \%$ of all deaths $(9 \%$ of all male deaths and $11 \%$ of all female deaths), that is about 400,000 deaths per year in the European community countries. Stroke is the second leading cause of death above the age of 60 years and the fifth leading cause in people aged 15 to 59 years (Hachinski, 2002). Stroke accounted for about one of every 16 deaths in the USA in 2004. About $50 \%$ of stroke deaths in 2003 occurred out of hospital. There was 150,147 (58,660 males, 91,487 females) stroke-related deaths in 2004 (American Heart Association, 2007). The period of highest risk is within the first 30 days, depending, in part, on stroke subtype. Almost $10 \%$ of subarachnoid haemorrhage patients die before hospitalisation, with a very high fatality rate in the first 2 days. In contrast to cerebral infarction, where deaths begin to 
occur within a few days to a few weeks, survival following subarachnoid haemorrhage has increased over time, partly due to better diagnosis of less severe cases by using computed tomography scanning and angiography (Ingall, 2004). The 1-year overall survival of stroke is roughly the same for men and women and has improved during the last years, thanks to a combination of factors, including a reduction in stroke severity at onset associated with increased detection of small, less severe strokes and better care of stroke patients. Survival at 5 years is significantly better for transient ischaemic attack (TIA) than an ischaemic stroke (Whisnant, 1993).

In addition to medical factors including previous TIA or stroke, ischaemic heart disease or atrial fibrillation, the likelihood of having a favourable outcome decreased with increasing age. Apart from biological traits such as age and sex, risk factors for stroke may refer to physiological characteristics such as high blood pressure, serum cholesterol, fibrinogen; behaviours such as smoking, diet, alcohol consumption, physical inactivity; social characteristics like education, social class and ethnicity; and environmental factors that may be physical (temperature, altitude), geographical or psychosocial. At a population level, blood pressure and tobacco use are the two most important modifiable risk factors for stroke due to their strong associations, high prevalence and the possibility for intervention (Shinton and Beevers, 1989; Elkind and Sacco, 1998).

As well as producing a high mortality burden, cerebrovascular disease is the leading cause of disability in adults, and each year millions of stroke survivors have to adapt to a life with restrictions in activities of daily living. Many surviving stroke patients will often depend on other people's continuous support to survive. One measure that takes into account the burden due to both deaths and disability for a particular disease is Disability Adjusted Life Years (DALYs), which is measured in days of potential life lost due to premature death and disability. The WHO Burden of Disease study uses DALYs to estimate the burden of disease. There were almost 50 million DALYs lost worldwide to stroke in 1999 . This is almost $8.4 / 1,000$ people, representing $3.5 \%$ of the total burden of all diseases. There is significant variation between regions in the total disease burden, from around 4.4 to 23.0 DALYs per 1,000 (World Health Organization, 2004). In the Family Heart Study of National Heart Lung and Blood Institute, among 108 ischaemic stroke survivors who were at least 65 years old, these disabilities were observed at 6 months after stroke: $50 \%$ had some hemiparesis, $30 \%$ were unable to walk without some assistance, $26 \%$ were dependent on activities of daily living, 19\% had aphasia, $35 \%$ had depressive symptoms and $26 \%$ were institutionalised in a nursing home (American Heart Association, 2007).

A significant improvement in acute stroke morbidity and mortality could be achieved by the reorganisation of stroke care services with the goal of rapidly evaluating and treating acute stroke patients. Acute ward area with stroke-dedicated beds (at least $80 \%$ of admitted patients are stroke patients) and dedicated teams (at least one full-time physician and nurse were caring exclusively for acute stroke patients), the so-called stroke unit (SU), are implemented to face acute stroke patients. Clinical trials and meta-analysis have consistently demonstrated the effectiveness of SU services for hospitalised stroke patients, reducing the number of survivors who depend on others for support either at home or in a healthcare facility. To determine whether admission to an $\mathrm{SU}$, rather than a conventional ward, affected the outcome of patients with acute stroke, an observational study was conducted in Italy between 2000 and 2004 (Candelise et al., 2007). Data were collected on about 11,572 acute stroke patients hospitalised within 
48 hours of the onset of symptoms either in an SU (43\%) or in a conventional ward (57\%). The study showed that there was an association between SU care provided in the acute phase of the disease and improvement of stroke outcome. In this setting, SU care could reduce in-hospital case fatality and also increase the proportion of patients living independently about 2 years after discharge. Provided admission occurs within 48 hours of onset, patients with acute stroke should be treated in SU wards with dedicated beds and staff, irrespective of age.

The expected number of new stroke events, based on the WHO stroke estimates and the United Nation's population projections, indicates that there will be an increase in the absolute number of stroke events from approximately 1.1 million per year in 2000 to 1.5 million per year in 2025 , even with stable stroke incidence rates. If the exposure to main modifiable risk factors of stroke would increase or be controlled, the estimated effect of slight increases or decreases in stroke incidence rates $( \pm 2 \%$ per 5 years) could lead to the difference by 2025 of $\pm 150,000$ stroke events when compared with stable rates (Truelsen et al., 2006). These numbers strongly suggest for intensifying prevention of stroke, as improving SUs for treatment and rehabilitative care.

\subsection{Socioeconomic implications of stroke}

Many economic resources in the diagnostic, therapeutic and rehabilitative phases are absorbed by stroke involving professionals, institutional and non-institutional facilities.

The costs of stroke depend on casing mix, types of stroke care provided, age, gender and severity. The estimates of the Cost-of-Illness approach provide information that describes the resources used and potential resources lost related to stroke. According to that, three categories of stroke-related costs may be identified:

Direct costs are borne by the healthcare system, community and family in directly addressing the problem (e.g. hospital care, physicians services, nursing home care, drugs); they basically consist of goods and services provided for preventing, diagnosing and treating the stroke disease and the medical consequences of it as well as for the rehabilitation services. Direct costs also include the out-of-pocket expenditures incurred by patient and family. This category of costs is mainly influenced by the length of stay in hospital, which largely depends on the severity of stroke and the death after stroke in hospital or needs for rehabilitation care and long-term care (Saxena et al., 2006).

Indirect costs include non-medical societal costs such as productivity losses caused by the disease, borne by the individual, family, society and/or employer, such as shortterm absence from work, early retirement or premature mortality.

Intangible costs are usually the costs of pain, suffering, loss of leisure time, loss of companionship and other non-financial impacts.

In the USA, the direct and indirect cost of cardiovascular diseases has been estimated at $\$ 431.8$ billion in 2007 , of which $\$ 62.7$ billion was attributable to stroke (American Heart Association, 2007). Direct costs were about $66 \%$ of the stroke costs (hospital cost $\$ 17.9$ billion, nursing home cost $\$ 15.2$ billion, physicians/other professionals cost $\$ 3.5$ billion, medical durable cost $\$ 1.2$ billion and home healthcare cost $\$ 3.8$ billion). The mean lifetime cost of ischaemic stroke has been estimated at $\$ 140,048$ including inpatient care, rehabilitation and follow-up care essential for lasting deficits. In the baseline scenario, the most important cost component for stroke care is the continuing care such as 
long-term nursing care, community-based care and social support services (Sundberg, Bagust and Terént, 2003). The increased use of continuing care and rehabilitation services raises the costs of stroke care. Moreover, better diagnosis and more appropriate treatments allow reduced unknown strokes relatively more than other types of stroke; as a result, some deaths will be avoided and stroke disabilities in the population can be expected to increase.

A summary of selected European studies on stroke costs per patient is shown in Table 1 (Truelsen et al., 2006).

Table 1 A summary of selected studies on costs per patient in some European countries

\begin{tabular}{|c|c|c|c|c|}
\hline Studies & Country & Cost categories & $\begin{array}{l}\text { Sample size } \\
\text { (number of patients) }\end{array}$ & $\begin{array}{l}\text { Costs per patient adjusted } \\
2004 \text { Euro }^{a}\end{array}$ \\
\hline $\begin{array}{l}\text { Carod-Artal } \\
\text { et al. (1999) }\end{array}$ & Spain & $\begin{array}{l}\text { Direct medical } \\
\text { costs }\end{array}$ & 118 & 5,435 during the first year \\
\hline $\begin{array}{l}\text { Ghatnekar } \\
\text { et al. (2004) }\end{array}$ & Sweden & $\begin{array}{l}\text { Direct and } \\
\text { indirect costs }\end{array}$ & $\begin{array}{l}4,357 \text { from the } \\
\text { nationwide register } \\
\text { Risks Stroke }\end{array}$ & $\begin{array}{l}13,903 \text { in direct costs } \\
\text { during the first year }\end{array}$ \\
\hline $\begin{array}{l}\text { Grieve et al. } \\
(2000)\end{array}$ & UK & Direct costs & $\begin{array}{l}328 \text { from the South } \\
\text { London Stroke Register }\end{array}$ & 7,393 during the first year \\
\hline $\begin{array}{l}\text { Porsdal } \\
\text { and } \\
\text { Boysen } \\
(1999)\end{array}$ & Denmark & $\begin{array}{l}\text { Direct medical } \\
\text { and } \\
\text { non-medical } \\
\text { costs }\end{array}$ & $\begin{array}{l}475 \text { with intracerebral } \\
\text { haemorrhage }(90) \text {, } \\
\text { cerebral infarct or } \\
\text { unspecified stroke (385) }\end{array}$ & 9,815 during the first year \\
\hline $\begin{array}{l}\text { Spieler et al. } \\
(2002)\end{array}$ & France & $\begin{array}{l}\text { Direct medical } \\
\text { costs }\end{array}$ & 494 & 20,114 over 18 months \\
\hline $\begin{array}{l}\text { van Exel } \\
\text { et al. (2003) }\end{array}$ & Netherlands & $\begin{array}{l}\text { Direct medical } \\
\text { and } \\
\text { non-medical } \\
\text { costs }\end{array}$ & 598 & 16,048 over 6 months \\
\hline $\begin{array}{l}\text { Weimar } \\
\text { et al. }(2003)\end{array}$ & Germany & $\begin{array}{l}\text { Direct and } \\
\text { indirect costs }\end{array}$ & 586 & 20,239 over 1 year \\
\hline $\begin{array}{l}\text { Andersson } \\
\text { et al. (2002) }\end{array}$ & Sweden & $\begin{array}{l}\text { Inpatient costs } \\
\text { and social } \\
\text { services }\end{array}$ & 121 & $\begin{array}{l}26,557 \text { during the first } \\
\text { year }\end{array}$ \\
\hline $\begin{array}{l}\text { Bergman } \\
\text { et al. (1995) }\end{array}$ & Netherlands & $\begin{array}{l}\text { Lifetime direct } \\
\text { costs }\end{array}$ & 24,007 & $\begin{array}{l}33,604 \text { for women; } 28,716 \\
\text { for men }\end{array}$ \\
\hline $\begin{array}{l}\text { Claesson } \\
\text { et al. }(2000)\end{array}$ & Sweden & $\begin{array}{l}\text { Direct medical } \\
\text { and non- } \\
\text { medical costs }\end{array}$ & 249 & $\begin{array}{l}25,493 \text { during the first } \\
\text { year }\end{array}$ \\
\hline $\begin{array}{l}\text { Dodel et al. } \\
\text { (2004) }\end{array}$ & Germany & $\begin{array}{l}\text { Direct medical } \\
\text { and } \\
\text { non-medical } \\
\text { costs }\end{array}$ & $\begin{array}{l}340 \text { admitted for stroke } \\
\text { (or TIA) }\end{array}$ & $\begin{array}{l}3,515 \text { for isachemic stroke } \\
\text { and } 5,131 \text { for intracerebral } \\
\text { haemorrhage } \\
\text { (per admission) }\end{array}$ \\
\hline $\begin{array}{l}\text { Levy et al. } \\
(2003)\end{array}$ & France & $\begin{array}{l}\text { Direct medical } \\
\text { costs }\end{array}$ & $\begin{array}{l}\text { Patients from CAPRIE } \\
\text { trial }\end{array}$ & 6,250 over 2 years \\
\hline
\end{tabular}


Table 1 A summary of selected studies on costs per patient in some European countries (continued)

\begin{tabular}{|c|c|c|c|c|}
\hline Studies & Country & Cost categories & $\begin{array}{l}\text { Sample size } \\
\text { (number of patients) }\end{array}$ & $\begin{array}{l}\text { Costs per patient adjusted } \\
2004 \text { Euro }^{a}\end{array}$ \\
\hline $\begin{array}{l}\text { Patel et al. } \\
(2004)\end{array}$ & UK & $\begin{array}{l}\text { Direct medical } \\
\text { and } \\
\text { non-medical } \\
\text { costs }\end{array}$ & $\begin{array}{l}447 \text { acute stroke patients } \\
\text { randomly assigned to } \\
\text { stroke unit, stroke team } \\
\text { or domiciliary stroke } \\
\text { care }\end{array}$ & $\begin{array}{l}\text { First year costs: } 16,403 \\
\text { for stroke unit; } 13,648 \text { for } \\
\text { stroke team; and } 9,799 \text { for } \\
\text { domiciliary stroke care }\end{array}$ \\
\hline $\begin{array}{l}\text { Terent et al. } \\
\text { (1994) }\end{array}$ & Sweden & $\begin{array}{l}\text { Direct and } \\
\text { indirect costs }\end{array}$ & $\begin{array}{l}162+125 \text { patients in } \\
\text { two populations }\end{array}$ & $\begin{array}{l}26,043 \text { during the first } \\
\text { year and } 20,715 \text { during } \\
\text { the second in the first } \\
\text { population }(\mathrm{N}=162) \text {. } \\
\text { Slightly lower in the } \\
\text { second one }\end{array}$ \\
\hline $\begin{array}{l}\text { Zethraeus } \\
\text { et al. (1999) }\end{array}$ & Sweden & $\begin{array}{l}\text { Direct medical } \\
\text { and } \\
\text { non-medical } \\
\text { costs }\end{array}$ & 25 & $\begin{array}{l}23,666 \text { during the first } \\
\text { year }\end{array}$ \\
\hline
\end{tabular}

Note: ${ }^{\mathrm{a}}$ Eur Stat (2004a), Eurostat (2004b) and European Central Bank (2004).

The costs of acute stroke vary throughout European countries depending on the model of care adopted: the duration of stay in hospital; daily input from therapists; the use of investigations; daily availability of doctors; the costs of employing healthcare professionals.

Several categories of stroke costs could be identified according to organising features as:

1 initial acute hospital stay

2 rehabilitation unit stay

3 ambulatory costs

4 community costs (Grieve et al., 2001b).

In addition to acute units caring for patients for 7 days after stroke and rehabilitation units that admit patients afterwards, integrated SUs identify these functions simultaneously. Comparing costs between different wards, SUs are more expensive than traditional wards (i.e. general and neurology wards), but have better results in terms of efficacy and cost-effectiveness. An Italian study shows that the length of stay in an SU is more expensive than the traditional one due to a higher intensity of medical treatments, whereas mortality, disability and rehabilitative phase costs are reduced (Miceli, 2002). In France, the total cost per patient over 5 years has been estimated $€ 30,983.28$ for a conventional care unit and $€ 34,683.09$ for an SU, and in terms of efficacy, treatment in SUs provides a benefit of 2.69 trimesters of survival without disability. The expenditure required for conventional care of 120,000 new strokes a year in France would be $€ 3,718$ million over 5 years (31\% long-stay institution, $28 \%$ rehabilitation unit, $28 \%$ home care, $13 \%$ hospital); the corresponding figure for SUs is $€ 4,156$ million (34\% long-stay institution, 25\% rehabilitation unit, 29\% home care, 12\% hospital) (Launois et al., 2004). 
Apart from hospital costs, other institution care costs as rehabilitation centres costs and nursing home costs could be identified. Hospital costs include accommodation costs, medication costs, assessment, medical and paramedical treatments, rehabilitation centres costs consider primary the accommodation costs as for nursing home costs. In addition costs for patients who stay at home could be considered as home care, paramedical care, general practitioner visit, cost of medication, home adaptations and assistive devices (van Exel et al., 2003).

The direct costs during the first months after stroke depend on the duration of the stay in hospital, and on the characteristics of the patients (age, gender, place of residence/having a partner).

The length of stay in hospital is the greater component of direct cost in stroke healthcare; it depends on several factors such as lower risk of mortality, different degree of stroke severity and length of waiting lists for nursing homes (Diringer et al., 1999). Variations in the lengths of hospital stay affect the mean total costs: centres with average stay over 30 days have the highest costs (Grieve et al., 2001a).

The cost of institution care (hospital, rehabilitation centre and nursing home) grows with the degree of disability, specially for ambulatory care (van Exel et al., 2003). Treatment of patients with mild and severe disability is the most expensive: within 30 days of an acute event, the average cost for mild isachemic strokes has been estimated as $\$ 13,019$ and for severe isachemic strokes as $\$ 20,346$ (4 or 5 on the Rankin Disability Scale) (American Heart Association, 2007). Disability due to a stroke event is a crucial financial factor as regards to the dimension of increasing problem, the severity of disability degree and the sustainability of overall spending. The need for rehabilitation services is expected to increase due to the decrease in age standardised mortality rate of stroke patients and the increase in ageing population in developed countries.

Generally, the wait for discharge is too long than the real need for medical treatments, so about 10 of the average 28 days to stay in hospital after stroke are estimated to have no medical reasons and consequently many blocked beds cannot be used for new patients needing acute treatment (van Exel et al., 2003). Managing care factors may improve cost-efficiency of care for stroke patients, reducing waiting lists for nursing home and home care and for this way discharging patients from expensive hospital beds. A disease management in terms of stroke service has to be pursued giving the right care at the right time in the right place from the right professional. A stroke service can be defined as 'a regional chain of caregivers: medical, nursing and therapy staff, who together, as a network, warrant integrated expert and coherent treatment and care for stroke patients in all phases: acute, rehabilitation and chronic of the ailment' (van Exel et al., 2003).

\section{Approach to neurorehabilitation: an outline of the ADD}

Data shown in previous section suggest the importance of improving the effectiveness of the neurorehabilitation process after the occurrence of stroke.

Functional recovery could be achieved mostly during the first months after the stroke event that is essential in terms of motor skill stimulations. In that period, evaluations about patients' conditions and rehabilitation recovery are regularly performed in the clinical practice by evaluation scales measuring functionalities or impairment's level of stroke patients. At present, qualitative methods are employed despite the fact that they are not so specific and fine to classify each patient based on his/her grade of severity. 
Moreover, patients assessed with qualitative scales are often grouped together according to very broad categories of stroke severity.

An innovative method for decision support in neurorehabilitation could be achieved through the use of ADD (Mazzoleni et al., 2005). ALLADIN is an innovative platform for whole-body isometric force measurements, which aims to assess the functional recovery outcome in neurorehabilitation and support the clinical decision making towards the choice of the best rehabilitative process for each patient. It calculates and predicts the functional recovery of stroke patients and makes clinical assessments and quantitative measurements easily exchangeable among clinical stroke rehabilitation units. Its purpose is to give quantitative measures for assessing functional recovery, to be compared with the qualitative methods at present used the clinical practice (e.g. evaluation scales). With the description through the natural language, a more detailed description and classification of each patient can be performed.

\section{The proposed theoretical/methodological approach}

A theoretical model is proposed in this section with the aim to frame the cost-saving implications related to the use of the ALLADIN ADD - once at the best running - for the clinical assessment of stroke patients. A traditional approach is compared to the ALLADIN one, considering the diagnostic and the rehabilitative steps of the assistive route for a stroke patient. Both approaches are graphically represented and summarised in Figure 1:

Figure 1 The methodological approach to ALLADIN

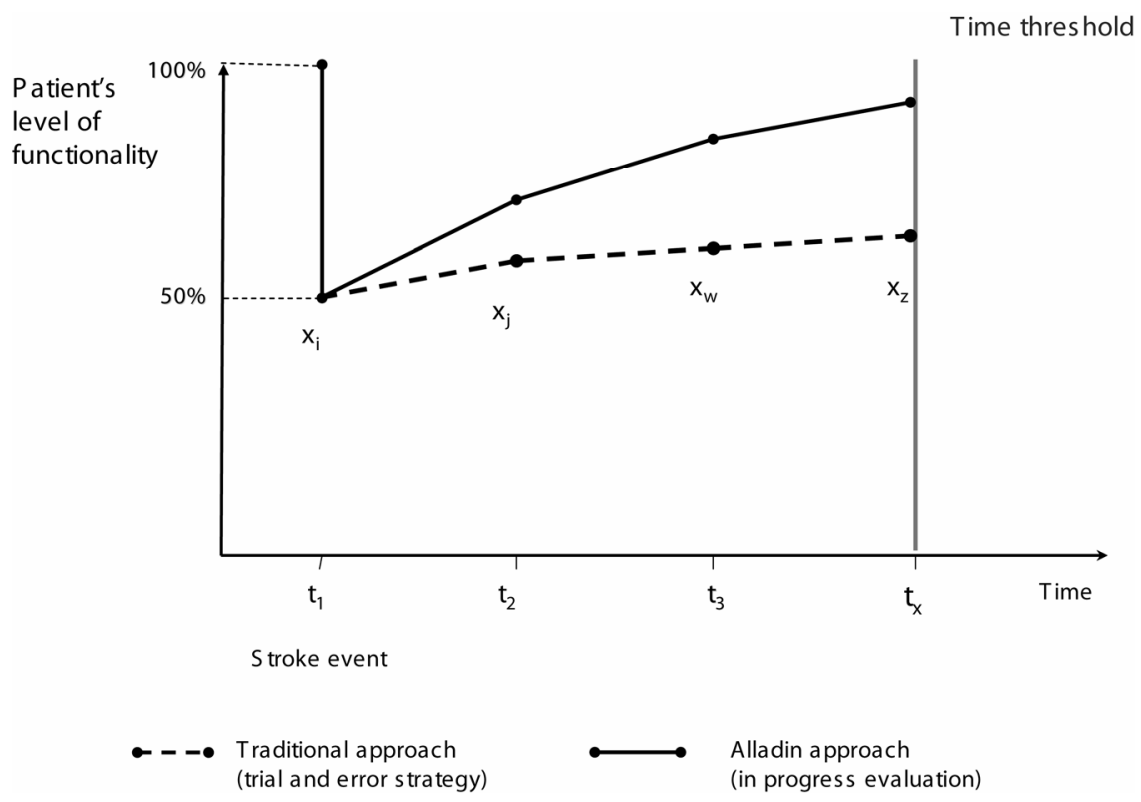


Supposing the stroke occurred at $t_{1}$, a loss of functionality, hypothesised to be approximately $50 \%$, happens in the same time.

It is well established from the medical literature that the first months after the stroke are extremely important in terms of recovering functionality. During this period, patient's recovery, if any, will be periodically assessed using evaluation scales, as consequence of $x_{i}, x_{z}$ therapeutic strategies established at every $t_{j}, j=1 \ldots x$. After the $t_{x}$ month threshold, rehabilitative therapies get quite no incremental effects.

Moving along a trial-and-error strategy that is the one adopted until the most effective treatment, if any, is identified, further adjustments may be introduced in the settled therapy: from $x_{j}$ to $x_{w}$ and from $x_{w}$ to $x_{z}$ up to $t_{x}$ time, which is the time limit fixed in the model after the stroke event.

In this example, according to the model, the trial-and-error strategy produces very low incremental improvement in the functionality recovery of stroke patient; in the proposed example, in fact, the recovery is about $15 \%$ (from $50 \%$ level of functionality after stroke to $65 \%$ after treatment) for the therapeutic strategy $x_{i}$ and about $5 \%$ (reaching the final level of $70 \%$ after treatment at time $t_{x}$ ) for the therapeutic strategy $x_{w}$ at time $t_{x}$, whereas the therapeutic strategy $x_{j}$ which takes place at $t_{2}$ shows to have practically no effect.

The main advantage of the ALLADIN approach is to allow a precise assessment of both the severity of stroke and the level of lost functionality at time $t_{1}$, as long as an evaluation of the expected return from different potential therapeutic strategies, so:

- reducing the uncertainty in the definition of the right therapy

- allowing early and timely adjustments in the treatment strategy in a kind of fine tuning process

- allowing estimation of the expected level of recovery related to the $x_{i}$ therapeutic strategy

- $\quad$ selecting the most promising one among the $x$ options.

At the core, the final advantage of the 'in-progress evaluation' of the functional recovery on which the ALLADIN approach is based is to allow early readjustments in the therapeutic strategy in order to identify timely - and within the $x$ month time limit (the most valuable months) - the most efficacious treatment. The expected result is a higher level of recovered functionality.

It is worth to underline the strong implications of the ALLADIN approach in terms of healthcare - and social - costs and cost savings.

Cost savings rise mainly from the following elements:

- an early selection of the most promising therapeutic strategy basing on the reduction of uncertainty (trial and error implies costs and new costs ...)

- a reduced number of changes in the therapeutic approach

- a higher final level of recovered functionality (that is minimisation of residual disability)

- a better understanding of the time when to suspend or reduce the therapies because no/or very limited incremental benefits may be expected (the judgment about the prosecution of inefficacious treatments depends on ethical criteria, financial 
resources available or on possible psychological positive effects of the therapy (placebo effect) in any case, this choice pertains to the healthcare political sphere.

Cost savings refer to both public and private resources saved mainly as a consequence of a lower level of final residual disability. Applying again the Cost-of-Illness approach, considerable social cost savings, measured in direct, indirect and intangible costs, come from reducing the residual disability of the stroke patient.

According to forensic medical studies (Bargagna and Busnelli, 1995, 1996, 2001; Comandé, 2006), the relationship between the level of disability and its implications on the patient's life is not a linear one. In particular, it has been demonstrated that there is an exponential relationship: as the level of disability increases, the negative implications on the patient's life are higher and higher. A decline of conditions in a person with a severe level of disability has a more negative impact on his/her life conditions than may have the same decline effect on a person with a mild level of disability. The negative impact, in terms of marginal damage, increases as the patient level of disability increases (Turchetti, 1996, 2001; Comandé and Turchetti, 2001; Turchetti and Labella, 2006).

If we consider that the costs of taking care of a disabled person grow in accordance with the negative effects on life conditions due to the disability decline, we can assert that the usefulness of ALLADIN (that is expected to allow the reaching of a higher final level of functionality recovered) in terms of socioeconomic savings increases as the level of disability increases (this relationship is graphically represented below).

The impact of an increasing level of disability on human life and the related increase in the cost of taking care of the disabled person show that the impact varies with the level of disability. In particular, the same increase of 5\% does not have the same economic effect if added to different starting levels of disability. An increase in disability from $25 \%$ to $30 \%$ (D1) will lead to an increase in cost of $\mathrm{C} 1$ whereas an increase from $75 \%$ to $80 \%$ (D2) will lead to a larger increase, namely, C2 (Figure 2).

Figure 2 Relationship between levels of disability and the cost for taking care of a disabled person

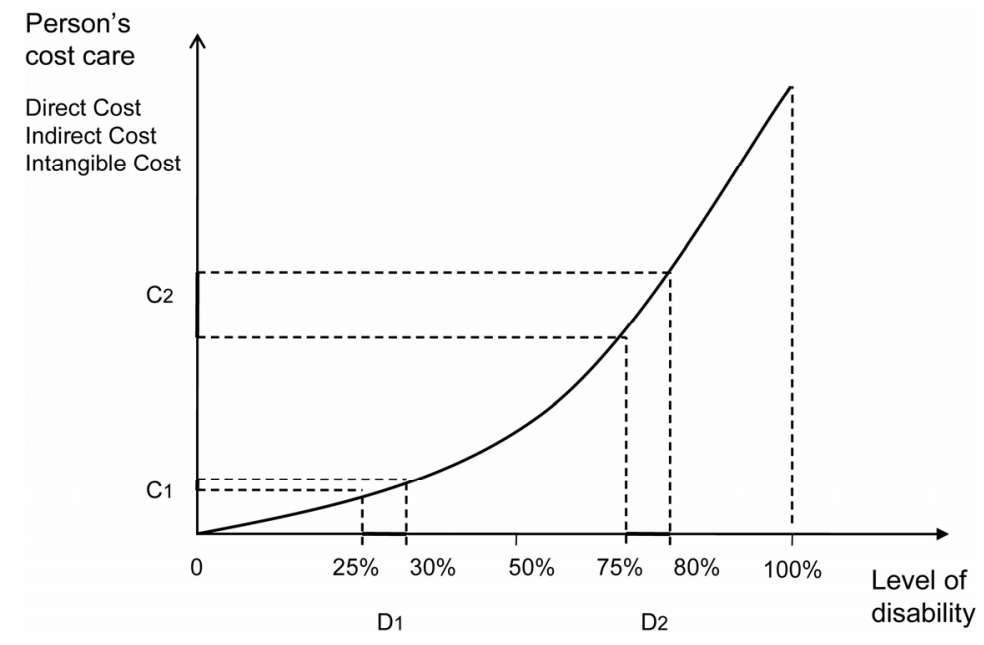


Therefore, in the theoretical approach proposed, we underline that an innovative diagnostic device as ALLADIN is always very useful, but its importance is higher in severe and very severe stroke than in stroke with a low level of severity; the savings in social costs increase as stroke severity increases.

The monetary evaluation of these savings is deeply country specific, and a further analysis would be interesting to be run.

\section{Conclusions}

The paper discusses a theoretical model for the assessment of social and economic benefits of a new neurorehabilitative technology allowing an in-progress evaluation of the diagnostic and the rehabilitative steps alongside the assistive route for a stroke patient if compared to the trial-and-error strategy pursued by a traditional one.

The model points out the potential social cost saving related to the application of the innovative technology for neurorehabilitation in stroke. Besides the direct cost savings, mainly related to a reduced number of changes in the therapeutic approach and to a better understanding of the time when to suspend or reduce the therapies, considerable social cost savings - both in public and private resources - measured in direct, indirect and intangible costs come from reducing the residual disability of the stroke patient.

The proposed theoretical approach is applied to the use of the ADD as an innovative technology in the field of post-stroke neurorehabilitation diagnostic and assessment process, but it could be generalised to both robot-mediated rehabilitation therapies and other diseases involving different levels of disabilities, such as neurological pathologies.

\section{References}

American Heart Association (2007) 'Heart disease and stroke statistics', Available at: http://www.americanheart.org/.

Andersson, A., Levin, L.A., Oberg, B. and Mansson, L. (2002) 'Health care and social welfare costs in home-based and hospital-based rehabilitation after stroke', Scandinavian Journal of Caring Sciences, Vol. 16, pp.386-392.

Bargagna, M. and Busnelli F.D. (2001) La Valutazione del Danno alla Salute: Profili Giuridici, Medico-Legali ed Assicurativi. Padova, Italy: CEDAM.

Bargagna, M. and Busnelli, F.D. (1995) La Valutazione del Danno alla Salute: Profili Giuridici, Medico-Legali ed Assicurativi. Padova, Italy: CEDAM.

Bargagna, M. and Busnelli, F.D. (1996) Rapporto sullo stato della giurisprudenza in tema di danno alla salute. Padova, Italy: CEDAM.

Bergman, L., van der Meulen, J.H., Limburg, M. and Habbema, J.D. (1995) 'Costs of medical care after firstever stroke in The Netherlands', Stroke Vol. 26, pp.1830-1836.

Brainin, M., Bornstein, N., Boysen, G. and Demarin, V. (2000) 'Acute neurological stroke care in Europe: results of the European Stroke Care Inventory', European Journal of Neurology, Vol. 7, pp.5-10.

Candelise, L., Gattinoni, M., Bersano, A., Micieli, G., Sterzi, R. and Morabito, A. (2007) 'Stroke-unit care for acute stroke patients: an observational follow-up study', Lancet, Vol. 27, No. 369, pp.299-305.

Carod-Artal, F.J., Egido-Navarro, J.A., Gonzalez-Gutierrez, J.L. and Varela de Seijas, E. (1999) 'Direct cost of cerebrovascular disease during the first year of followup', Rev Neurol, Vol. 28, pp.1123-1130. 
Claesson, L., Gosman-Hedstrom, G., Johannesson, M., Fagerberg, B. and Blomstrand, C. (2000) 'Resource utilization and costs of stroke unit care integrated in a care continuum: A 1-year controlled, prospective, randomized study in elderly patients: the Goteborg. $70+$ Stroke Study', Stroke, Vol. 31, pp.2569-2577.

Comandé, G. (2006) Gli strumenti della precauzione: nuovi rischi, assicurazione e responsabilità. Milano, Italy: Giuffrè.

Comandé, G. and Turchetti, G. (2001) 'Il disegno di legge sul danno biologico presentato dal Governo: il suo impatto sistematico e il sistema tabellare', in M. Bargagna and F.D. Busnelli (Eds.) La Valutazione del Danno alla Salute: Profili Giuridici, Medico-Legali ed Assicurativi. Padova, Italy: CEDAM.

Di Carlo, A., Launer, L.J., Breteler, M.M., Fratiglioni, L., Lobo, A., Martinez Lage, J., Schmidt, R. and Hofman, A. (2000) 'Frequency of stroke in Europe: a collaborative study of population-based cohorts. ILSA Working Group and the Neurologic Diseases in the Elderly Research Group. Italian Longitudinal Study on Aging', Neurology, Vol. 54, S28-S33.

Diringer, M.N., Edwards, D.F., Mattson, D.T., Akins, P.T., Sheedy, C.W., Hsu, C.Y. and Dromerick, A.W. (1999) 'Predictors of acute hospital costs for treatment of ischemic stroke in an academic center', Stroke, Vol. 30, pp724-728.

Dodel, R., Haacke, C., Zamzov, K. and Pawelzik, S. (2004) 'Resource utilization and cost of stroke unit care in Germany', Value Health, Vol. 7, pp.144-152.

Elkind, M. and Sacco, R. (1998) 'Stroke risk factors and stroke prevention', Seminars in Neurology, Vol. 18, pp.429-440.

European Central Bank (2004) Statistics. Available at: http://www.ecb.int/stats/exchange/eurofxref/ $\mathrm{html} /$ index.en.html.

Eurostat (2004a) Economy and Finance. Comparative price levels. Eurostat Yearbook 2004. Brussels: Eurostat.

Eurostat (2004b) Economy and Finance. Harmonised Annual Average Consumer Price Indices. Eurostat Yearbook 2004. Brussels: Eurostat.

Feigin, V.L., Lawes, C.M., Bennett, D.A. and Anderson, C.S. (2003) 'Stroke epidemiology: a review of population-based studies of incidence, prevalence, and case-fatality in the late 20th century', Lancet Neurology, Vol. 2, pp.43-53.

Ghatnekar, O., Persson, U., Glader, E. and Terent, A. (2004) 'Cost of stroke in Sweden: an incidence estimate', Int. J. Technology Assessment in Health Care, Vol. 20, pp.375-380.

Grieve, R., Dundas, R., Beech, R. and Wolfe, C. (2001a) 'The development and use of a method to compare the costs of acute stroke across Europe', Age and Ageing, Vol. 30, pp.67-72.

Grieve, R., Hutton, J., Bhalla, A., Rastenyte, D., Ryglewicz, D., Sarti, C., Lamassa, M., Giroud, M., Dundas, R. and Wolfe, C.D.A. (2001b) 'A comparison of the costs and survival of hospitaladmitted stroke patients across europe', Stroke, Vol. 32, pp.1684-1691.

Hachinski, V. (2002) 'Stroke: the next 30 years', Stroke, Vol. 33, No. 1, pp.1-4.

Ingall, T. (2004) 'Stroke - incidence, mortality, morbidity and risk', Journal of Insurance Medicine, Vol. 36, pp.143-152.

Jorgensen, H.S., Nakayama, H., Raaschou, H.O. and Olsen, T.S. (1999) 'Stroke. Neurologic and functional recovery the Copenhagen Stroke Study', Physical Medicine and Rehabilitation Clinics of North America, Vol. 10, No. 4, pp.887-906.

Launois, R., Giroud, M., Mégnigbêto, A.C., Le Lay, K., Présenté, G., Mahagne, M.H., Durand, I. and Gaudin, A.F. (2004) 'Estimating the cost-effectiveness of stroke units in France compared with conventional care', Stroke, Vol. 35, pp.770-775.

Levy, E., Gabriel, S. and Dinet, J. (2003) 'The comparative medical costs of atherothrombotic disease in European countries', Pharmacoeconomics, Vol. 21, pp.651-659.

Mazzoleni, S., Van Vaerenbergh, J., Toth, A., Munih, M., Guglielmelli, E. and Dario, P. (2005) 'ALLADIN: a novel mechatronic platform for assessing post-stroke functional recovery', Paper presented in the Proceedings of the International Conference on Rehabilitation Robotics, Chicago, IL, pp.156-159. 
Miceli, G. (2002) 'Economia Sanitaria delle Stroke Unit', The Italian Stroke Forum Newsletter, Vol. 3 No. 2, p.4.

Patel, A., Knapp, M., Perez, I., Evans, A. and Kalra, L. (2004) 'Alternative strategies for stroke care: cost-effectiveness and cost-utility analyses from a prospective randomized controlled trial', Stroke, Vol. 35, pp.196-203.

Porsdal, V. and Boysen, G. (1999) 'Costs of health care and social services during the first year after ischemic stroke', Int. J. Technology Assessment in Health Care, Vol. 15, No. 3, pp.573-584.

Saxena, S.K., Ng, T.P., Yong, D., Fong, N.P. and Gerald, K. (2006) 'Total direct cost, length of hospital stay, institutional discharges and their determinants from rehabilitation settings in stroke patients', Acta Neurologica Scandinava, Vol. 114, pp.307-314.

Shinton, R. and Beevers, G. (1989) 'Meta-analysis of relation between cigarette smoking and stroke', British Medical Journal, Vol. 298, pp.789-795.

Spieler, J.F., Lanoe, J.L. and Amarenco, P. (2002) 'Socioeconomic aspects of postacute care for patients with brain infarction in France', Cerebrovasc Dis, Vol. 13, pp.132-141.

SPREAD (2005) Stroke Prevention and Educational Awareness Diffusion (4th ed.), Milano, Italy: Catel - Hyperphar Group SpA.

Sundberg, G., Bagust, A. and Terént, A. (2003) 'A model for costs of stroke service', Health Policy, Vol. 63, pp.81-94.

Terent, A., Marke, L.A., Asplund, K., Norrving, B., Jonsson E. and Wester, P.O. (1994) 'Costs of stroke in Sweden. A national perspective', Stroke Vol. 25, pp.2363-2369.

Truelsen, T., Begg, S. and Mathers, C. (2003) The Global Burden of Cerebrovascular Disease. Geneva: World Health Organization.

Truelsen, T., Piechowski-Jozwiak, B., Bonita, R., Mathers, C., Bogousslavsky, J. and Boysen, G. (2006) 'Stroke incidence and prevalence in Europe: a review of available data', European Journal of Neurology, Vol. 13, pp.581-598.

Turchetti, G. (1996) 'Gli sviluppi dello studio sulla determinazione del valore monetario base del punto di invalidità', in M. Bargagna and F.D. Busnelli (Eds), Rapporto sullo stato della giurisprudenza in tema di danno alla salute. Padova, Italy: CEDAM, pp.171-201.

Turchetti, G. (2001) 'Una Ipotesi di Costruzione della Tabella dei Valori Monetari Base del Punto di Invalidità', in M. Bargagna and F.D. Busnelli (Eds) La Valutazione del Danno alla Salute: Profili Giuridici, Medico-Legali ed Assicurativi. Padova, Italy: CEDAM, pp.629-669.

Turchetti, G. and Labella, B. (2006) 'L'innovazione nelle tecnologie biomediche tra rischio, incertezza, precauzione e gestione', in G. Comandé, (Eds), Gli strumenti della precauzione: nuovi rischi, assicurazione e responsabilità. Milano, Italy: Giuffrè, pp.367-395.

van Exel, J., Koopmanschap, M.A., van Wijngaarden J.D.H. and Scholte op Reimer W. J.M. (2003) 'Costs of stroke and stroke services: determinants of patient costs and a comparison of costs of regular care and acre organised in stroke services', Cost Effectiveness and Resource Allocation, Vol. 1, pp.1-11.

Weimar, C., Weber, C., Wagner, M., Busse, O., Haberl, R.L., Lauterbach, K.W. and Diener, H.C. (2003) 'Management patterns and health care use after intracerebral hemorrhage. A cost-ofillness study from a societal perspective in Germany. Cerebrovasc Dis, Vol. 15, pp.29-36.

Whisnant, J. (1993) 'Natural history of transient ischemic attack and ischemic stroke', in J. Whisnant (Ed), Stroke: Population, Cohorts, and Clinical Trials. Oxford: Butterworth-Heinemann Ltd., pp.135-153.

World Health Organization (2004) 'The atlas of heart disease and stroke', Available at: http://www.who.int/cardiovascular_diseases/resources/atlas/en/.

Zethraeus, N., Molin, T., Henriksson, P. and Jonsson, B. (1999) 'Costs of coronary heart disease and stroke: the case of Sweden', Journal of Internal Medicine, Vol. 246, pp.151-159. 